\title{
Stress neuroendocrine profiles in five pig breeding lines and the relationship with carcass composition
}

\author{
A. Foury ${ }^{1}$, N. A. Geverink ${ }^{1}$, M. Gil ${ }^{2}$, M. Gispert ${ }^{2}$, M. Hortós ${ }^{2}$, M. Font i Furnols ${ }^{2}$, \\ D. Carrion ${ }^{3}$, S. C. Blott ${ }^{4}$, G. S. Plastow ${ }^{4}$ and P. Mormède ${ }^{1 \dagger}$ \\ ${ }^{1}$ Laboratoire PsyNuGen, INRA UMR1286, CNRS UMR5226, Université Victor Segalen Bordeaux 2, 33076-Bordeaux, France; ${ }^{2} I R T A$ - Monells, Finca Camps i \\ Armet, E-17121 Monells, Spain; ${ }^{3}$ PIC International Group, 2 Kingston Business Park, Kingston Bagpuize, Oxfordshire OX13 5FE, UK; ${ }^{4}$ Sygen International, \\ 2 Kingston Business Park, Kingston Bagpuize, Oxfordshire OX13 5FE, UK
}

(Received 1 August 2006; Accepted 29 March 2007)

\begin{abstract}
Stress neuroendocrine systems (hypothalamic-pituitary-adrenal axis and sympathetic nervous system) were studied in 100 female pigs from each of the five main genetic lines used in Europe for pork production: Piétrain, Large White, Landrace, Duroc and Meishan. Levels of cortisol and catecholamines were measured in urine collected at the farm, after transportation to the slaughterhouse and the next morning before slaughter. With the exception of the Piétrain line that showed intermediate levels of cortisol despite its extreme leanness, a significant positive relationship was found between basal cortisol levels and fatness, both across and within (except in Piétrain and Duroc) lines. Basal cortisol levels were 2.46-fold higher in Meishan (20.46 ng/mg creatinine) than in Large White pigs $(8.30 \mathrm{ng} / \mathrm{mg}$ creatinine), the two extreme breeds. Post-transportation levels were highest but proportional to basal levels, suggesting that the adrenal reactivity to adrenocorticotropic hormone is a major source of variability between lines. Levels of catecholamines were less variable between lines but correlated also with fatness, partlyviapartial correlations with cortisol levels. In serum collected at exsanguination, creatine kinase activity was correlated with muscularity across the five breeds. However, this was due to a much larger activity than expected in Piétrain pigs, although all animals were negative for the allele of the ryanodine receptor gene responsible for stress sensitivity. Serum glucose levels were inversely related to fatness. These data show that the differences between breeds or lines can be utilised by cross-breeding and that this can lead to changes in stress hormones and in turn to some degree of changes in carcass traits.
\end{abstract}

Keywords: catecholamines, cortisol, fatness, genetics, stress

\section{Introduction}

The two main stress-responsive neuroendocrine systems play a critical role in the regulation of energy fluxes. The hypothalamic-pituitary-adrenocortical (HPA) axis influences feeding behaviour, pancreatic hormone secretion, energy expenditure and the protein/lipid balance (Dallman et al., 1993). Cortisol, the main hormone of the axis, released by the adrenal cortex, favours the accretion of fat at the expense of proteins (Devenport et al., 1989). Indeed, a pig breed like Meishan with a high carcass content of fat (Bidanel et al., 1993) also produces more cortisol (Bergeron et al., 1996; Hay and Mormède, 1998). On the other hand, catecholamines (adrenaline and noradrenaline) released by the sympathetic nervous system (SNS) increase the use of energy stores (glycogen and lipids) (Scheurink and Steffens,

\footnotetext{
${ }^{\dagger}$ E-mail: Pierre.Mormede@bordeaux.inra.fr
}

1990) and exert anabolic effects on protein metabolism (Navegantes et al., 2002). Sympathetic activation by stress before slaughter reduces muscle glycogen content and postmortem acidification, leading to dark, firm and dry-type (DFD) meat (Fernandez and Tornberg, 1991; Monin, 2003). In a recent study using an F2 segregating population between the Duroc and Large White breeds, we demonstrated that cortisol levels measured in urine collected in the bladder after slaughter correlated positively with fat contents of the carcass, and that urinary catecholamine levels correlated positively with ultimate $\mathrm{pH}$ of the meat (Foury et al., 2005). In the context of a larger study to explore the genetic components of meat quality (Plastow et al., 2005), the present experiment was designed to evaluate the activity of neuroendocrine stress systems in five genetic lines representing a significant proportion of European pig production, and study the relationship of neuroendocrine characteristics with carcass composition and meat quality. 
Foury, Geverink, Gil, Gispert, Hortós, Fonti Furnols, Carrion, Blott, Plastow and Mormède

\section{Material and methods}

\section{Animals}

The present study was carried out on 500 female pigs from five closed populations (breeding lines) representing a significant proportion of the breeds used in European pig production. The lines were based on Piétrain ( $\mathrm{Pl}, n=100)$, Large White (LW, $n=101)$, Landrace (LD, $n=99)$, Duroc (DU, $n=100$ ) and Meishan (MS, $n=100$ ) breeds (although in the latter case a Meishan/Large White crossbred line was used). The Piétrain line was normal (NN) for the 'halothane' gene. This line was closed in the 1980s and subject to selection against the halothane gene using halothane gas and subsequently the HAL1843 marker test (Fuji et al., 1991). Animals were reared under the same environment and production regime in a breeding nucleus farm in southwestern France. Data were collected on the farm for growth and ultrasonic back fat. At approximately 193 days of age, the animals were transported in 22 batches of around 25 to overnight lairage at a research abattoir in Spain (IRTA, Monells), from January 2002 to June 2003. The next morning (between 0700 and $1300 \mathrm{~h}$ ), animals were weighed (mean weight $109.4 \mathrm{~kg}$ ) and harvested after $\mathrm{CO}_{2}$ stunning ( $85 \%$ concentration). Carcass and meat quality data were collected. Great care was taken to minimise stress during handling and transportation, and animals from different rearing pens were not mixed. Each slaughter batch contained an equal number of animals from all genetic lines (except one batch due to the slight imbalance of the number of animals per line).

\section{Carcass composition measurements}

Measurements of fat (G34FOM) and muscle (M34FOM) depths at 45 min post mortem were made using the Fat-0Meater equipment (SFKTech, Denmark) at $60 \mathrm{~mm}$ from the mid-line between the 3rd and 4th last rib level. Estimated carcass lean content (PLEAN) was calculated using the Spanish official equation (Gispert and Diestre, 1994),

PLEAN $=61.56-0.878 \times$ G34FOM $+0.157 \times$ M34FOM

Approximately $1 \mathrm{~h}$ after slaughter, carcasses were chilled in a cold room at $2^{\circ} \mathrm{C}$. At $24 \mathrm{~h}$ post-mortem, muscle pH was measured using a Crison portable meter equipped with a xerolyt electrode (Crison, Barcelona, Spain) in the longissimus dorsi muscle at the level of the caudal end of the last rib, and in the semimembranosus muscle in the middle of the muscle in the exposed visible part. The surface area of the eye of the longissimus dorsi muscle was measured between the 3rd and 4th last rib level. This was done by making a transversal cut at this point and taking a digital image. This image was used to calculate the surface using a specific programme (Pomar et al., 2001). Each left half carcass was cut and dissected following the method of Walstra and Merkus (1995). In order to have more commercial cuts, some parts were joined as hind hand plus leg (ham), loin minus subcutaneous fat of the loin (loin) and belly. A sample of semimembranosus and longissimus dorsi muscles was taken for the determination of intramuscular fat content by near-infrared transmittance (Infratec 1265, FOSS Tecator, Sweden).

\section{Urine sampling and hormone assays}

Urine samples were collected to measure stress hormone levels (cortisol and catecholamines) (i) when spontaneously voided at the farm in the morning (between 0800 and $1000 \mathrm{~h}$ ) during the week preceding slaughter, (ii) when the animals arrived in the lairage area after approximately $10 \mathrm{~h}$ of transportation in a truck and (iii) the next morning before they were moved to the $\mathrm{CO}_{2}$ chamber. Urine was obtained from only part of the animals in the last two conditions ( $n=21$ to 36 and 36 to 59 per line, respectively). A preservative (ethylene diaminetetra acetic acid (EDTA) $10 \%$, $1 \mathrm{ml} / 40 \mathrm{ml}$ ) was added and samples were frozen until analysis.

Urinary cortisol was assayed using a solid-phase extraction procedure on $\mathrm{C} 18$ cartridges followed by HPLC with UV absorbance detection $(254 \mathrm{~nm})$, as previously described (Hay and Mormède, 1997b). The intra- and inter-assay coefficients of variation (\%) were 7.4 and 10.6 , respectively.

Urinary catecholamines (adrenaline and noradrenaline) were assayed using an ion-exchange purification procedure followed by HPLC with electrochemical detection, as previously described (Hay and Mormède, 1997a). The intraand inter-assay coefficients of variation (\%) were 7.0 and 7.1 for adrenaline, and 6.5 and 11.6 for noradrenaline, respectively.

Concentrations of hormones in urine were expressed as the ratio of creatinine content ( $\mathrm{ng} / \mathrm{mg}$ creatinine), to correct for the variable dilution of urine related to water intake (Crockett et al., 1993). Creatinine levels were determined using a colorimetric quantitative reaction (Creatinine, BIOLABO, Fismes, France).

\section{Blood sampling and biochemical assays}

Blood was collected during exsanguination in a dry tube, left at room temperature for $20 \mathrm{~min}$ for coagulation, and centrifuged. Serum aliquots were frozen until analysis. Cortisol was measured by radioimmunoassay as described (Désautés et al., 1997). Glucose, lactate and creatine kinase (CK) activity were measured with a clinical biochemistry automate (Hitachi 911) and assay kits from Roche diagnostics, Meylan, France.

\section{Statistics}

Serum cortisol levels and CK activity, as well as hormone levels in urine were transformed into their logarithmic score for data normalisation. Data were analysed using the MIXED procedure of Statistical Analysis Systems Institute (2000). Line, day of sampling (for urinary hormone data) and their interaction were included as fixed effects and batch as a random effect. Family relationships were accounted for by the inclusion of sire within genetic line as 
a random effect. Least-squares means were generated by the (LSMEANS) statement. Partial Pearson correlations corrected for batch were calculated between biological data and carcass composition traits with the PROC CORR. In order to test whether the subgroups of animals from which urine could be collected at the arrival to the slaughterhouse and/or the next morning were representative of the whole population, we compared the mean values of hormone levels (cortisol and catecholamines) measured in urine collected in basal conditions (first sample) in these subgroups of animals as compared with the whole population, with line and batch as fixed effects. No comparison reached significance. Similarly, these subpopulations did not differ from the whole population for carcass parameters like PLEAN. Therefore, we assume that these subgroups of animals from which a second and/or a third sample of urine could be collected were representative of the whole group of experimental animals.

\section{Results}

Carcass composition traits measured in these animals have been published before (Plastow et al., 2005; Geverink et al., 2006) and only a few selected measures are listed in Table 1. The genetic lines studied in the present experiment show a large variation in body composition and are ranked in the order of decreasing carcass lean content (PLEAN), from the leanest (Piétrain, 60.3\%) to the fattiest (Meishan, 48.8\%). The same line order is kept in Figure 1.

Biological variables measured in serum collected at exsanguination are shown in Table 1. Serum cortisol concentrations were highest in Meishan, lowest in Landrace and intermediate in the other lines (Duroc $<$ Large White $<$ Piétrain). Serum CK activity increased with increasing muscularity, but was much higher in Piétrain than would be expected from the extrapolation of the data obtained in the other lines (correlation between PLEAN and $\log$ CK: $r=0.14, P<0.01$ without the Piétrain line and $r=0.33, P<0.001$ with all the animals; see Table 2). Serum glucose concentrations were inversely related to the level of adiposity (Table 2). Variable concentrations of serum lactate were found, but altogether they were very low as compared with the values obtained in usual commercial conditions (e.g. Warriss et al., 1998; Pérez et al., 2002). This reflects the low stress level as a result of smooth handling of the animals.

Hormone concentrations measured in urine are shown in Figure 1. Basal cortisol concentrations measured in urine samples collected at the farm showed a very strong effect of line $(P<0.001)$, with concentrations being 2.46-fold higher in Meishan $(20.46 \mathrm{ng} / \mathrm{mg}$ creatinine) than in Large White pigs $(8.30 \mathrm{ng} / \mathrm{mg}$ creatinine). Urine cortisol concentrations increased between lines with increasing adiposity, except for Piétrain pigs that displayed intermediate concentrations of cortisol in urine $(15.11 \mathrm{ng} / \mathrm{mg}$ creatinine) despite their low fat content. Indeed, a negative correlation coefficient was found between PLEAN and basal urine cortisol concentrations $(r=-0.30, P<0.001)$ and the coefficient was much higher $(r=-0.46, P<0.001)$ when the group of Piétrain pigs was excluded from the analysis (Table 2). Significant positive correlation coefficients were found with all variables related to adiposity (flare fat, fat depth, intramuscular fat), and significant negative correlation coefficients were found with variables related to muscularity (PLEAN, area of the longissimus dorsi muscle, percentage of ham), except for the percentage of loin. In all cases, the correlation coefficients increased when Piétrain pigs were excluded from the analysis (Table 2). Within lines, significant correlations were found between basal urinary

Table 1 Least-squares means of carcass characteristics and serum variables in five genetic lines

\begin{tabular}{|c|c|c|c|c|c|c|c|}
\hline & \multirow[b]{2}{*}{$n$} & \multicolumn{5}{|c|}{ Genetic line } & \multirow[b]{2}{*}{ Pooled s.e } \\
\hline & & Piétrain & Large White & Landrace & Duroc & Meishan & \\
\hline Carcass weight $(\mathrm{kg})$ & 500 & $88.59^{x}$ & $90.74^{x y}$ & $89.70^{x y}$ & $91.63^{y}$ & $85.70^{w}$ & 0.744 \\
\hline Lean content (\%) $\left(\right.$ PLEAN) ${ }^{\dagger}$ & 500 & $60.33^{w}$ & $57.30^{x}$ & $57.10^{x}$ & $55.11^{y}$ & $48.78^{2}$ & 0.338 \\
\hline Flare fat (\%) & 500 & $5.65^{\mathrm{w}}$ & $5.56^{\mathrm{w}}$ & $7.20^{\mathrm{x}}$ & $6.93^{x}$ & $10.85^{y}$ & 0.238 \\
\hline Fat depth $(\mathrm{mm})^{\ddagger}$ & 500 & $12.99^{\mathrm{w}}$ & $15.17^{x}$ & $15.23^{x}$ & $17.80^{y}$ & $23.99^{2}$ & 0.378 \\
\hline Area longissimus dorsi $\left(\mathrm{cm}^{2}\right)$ & 500 & $57.33^{w}$ & $47.31^{x}$ & $47.81^{x y}$ & $48.49^{y}$ & $39.89^{2}$ & 0.694 \\
\hline $\operatorname{Ham}(\%)$ & 480 & $27.03^{\mathrm{w}}$ & $24.67^{x}$ & $25.03^{y}$ & $24.83^{x y}$ & $22.94^{z}$ & 0.097 \\
\hline Loin $(\%)$ & 480 & $16.84^{\mathrm{w}}$ & $16.90^{\mathrm{wx}}$ & $17.10^{x}$ & $17.36^{y}$ & $16.70^{w}$ & 0.126 \\
\hline Intramuscular fat semimembranosus (\%) & 495 & $1.49^{x}$ & $1.19^{w}$ & $1.53^{x}$ & $2.17^{\mathrm{y}}$ & $2.15^{y}$ & 0.080 \\
\hline Intramuscular fat longissimus dorsi (\%) & 498 & $1.23^{x}$ & $1.00^{\mathrm{w}}$ & $1.10^{\mathrm{wx}}$ & $1.81^{y}$ & $1.96^{y}$ & 0.063 \\
\hline Serum cortisol (ng/ml), log & 500 & $1.307^{y}$ & $1.232^{\mathrm{x}}$ & $1.146^{\mathrm{w}}$ & $1.183^{w x}$ & $1.455^{z}$ & 0.048 \\
\hline Serum creatine kinase (IU/I), log & 500 & $3.581^{\mathrm{w}}$ & $3.257^{x}$ & $3.205^{x y}$ & $3.178^{x y}$ & $3.160^{y}$ & 0.037 \\
\hline Serum glucose (mmol/l) & 500 & $7.94^{\mathrm{w}}$ & $7.54^{\mathrm{wx}}$ & $7.37^{x}$ & $6.82^{y}$ & $6.48^{y}$ & 0.16 \\
\hline Serum lactate $(\mathrm{mmol} / \mathrm{l})$ & 500 & $3.69^{y}$ & $2.87^{x y}$ & $4.00^{y}$ & $2.44^{\mathrm{w}}$ & $3.13^{x}$ & 0.16 \\
\hline
\end{tabular}

w, $x, y, z$ Means within a row lacking a common superscript differ $(P<0.05)$.

${ }^{\dagger}$ Calculated using the Spanish official equation.

${ }^{\ddagger}$ Fat depth measured with the Fat-0-Meater equipment at $60 \mathrm{~mm}$ from the mid-line between the 3rd and the 4th last rib level. 
Foury, Geverink, Gil, Gispert, Hortós, Fonti Furnols, Carrion, Blott, Plastow and Mormède
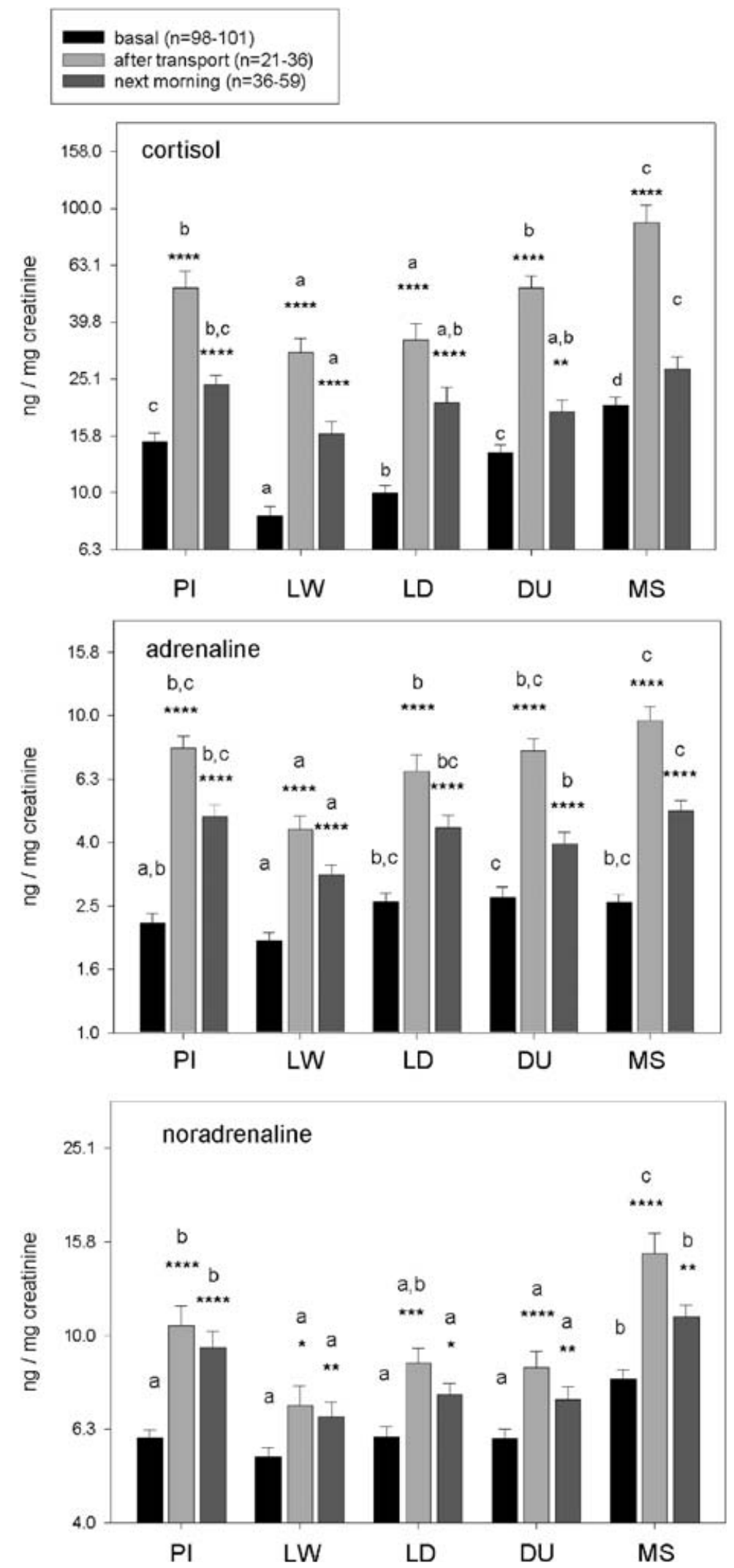

Figure 1 Concentrations of cortisol, adrenaline and noradrenaline in urine collected at the farm (basal), at arrival at the slaughterhouse (after transport) and the next morning before slaughter (mean \pm s.e.) for the five genetic lines: Piétrain (PI), Large White (LW), Landrace (LD), Duroc (DU) and Meishan (MS). Different letters indicate significant differences $(P<0.05)$ between breeds at the same collection time. Stars indicate the difference with basal levels for each genetic line $\left({ }^{*} P<0.05,{ }^{* *} P<0.01,{ }^{* *} P<0.001,{ }^{* * *} P<0.0001\right)$. 
Stress neuroendocrine systems in five pig lines

Table 2 Pearson partial correlation coefficients (corrected for batch) between biological measures and carcass composition traits ${ }^{\dagger}$

\begin{tabular}{|c|c|c|c|c|}
\hline \multirow[b]{2}{*}{ Trait $^{*}$} & \multicolumn{4}{|c|}{ Biological measure } \\
\hline & $\begin{array}{c}\text { Cortisol serum } \\
\text { (ng/ml), log }\end{array}$ & $\begin{array}{l}\text { Creatine kinase } \\
\text { serum (IU/I), log }\end{array}$ & $\begin{array}{l}\text { Glucose serum } \\
\quad(\mathrm{mmol} / \mathrm{l})\end{array}$ & $\begin{array}{c}\text { Cortisol urine } \\
\text { on farm } \\
\text { (ng/mg creatinine) }\end{array}$ \\
\hline \multirow[t]{2}{*}{ Lean content (PLEAN) } & $-0.25^{* * *}$ & $0.33^{* * *}$ & $0.26^{* * *}$ & $-0.30^{* * *}$ \\
\hline & $-0.34^{* * *}$ & $0.14^{* *}$ & $0.20^{* * *}$ & $-0.46^{* * *}$ \\
\hline \multirow[t]{2}{*}{ Flare fat (\%) } & $0.21^{* * * *}$ & $-0.19^{* * *}$ & $-0.22^{* * *}$ & $0.30^{* * * *}$ \\
\hline & $0.25^{* * *}$ & $-0.09^{\mathrm{ns}}$ & $-0.21^{* * *}$ & $0.38^{* * *}$ \\
\hline \multirow[t]{2}{*}{ Fat depth (mm) } & $0.25^{* * *}$ & $-0.27^{* * *}$ & $-0.26^{* * *}$ & $0.32^{* * *}$ \\
\hline & $0.34^{* * *}$ & $-0.11^{*}$ & $-0.21^{* * *}$ & $0.46^{* * *}$ \\
\hline \multirow[t]{2}{*}{ Area longissimus dorsi $\left(\mathrm{cm}^{2}\right)$} & $-0.14^{* *}$ & $0.44^{* * *}$ & $0.20^{* * *}$ & $-0.12^{* *}$ \\
\hline & $-0.28^{* * *}$ & $0.25^{* * *}$ & $0.13^{* *}$ & $-0.27^{* * *}$ \\
\hline \multirow[t]{2}{*}{$\operatorname{Ham}(\%)$} & $-0.14^{* *}$ & $0.46^{* * *}$ & $0.28^{* * *}$ & $-0.13^{* *}$ \\
\hline & $-0.34^{* * *}$ & $0.13^{*}$ & $0.18^{* * *}$ & $-0.35^{* * *}$ \\
\hline \multirow[t]{2}{*}{ Loin $(\%)$} & $-0.07^{\mathrm{ns}}$ & $0.01^{\mathrm{ns}}$ & $-0.05^{\mathrm{ns}}$ & $0.03^{\mathrm{ns}}$ \\
\hline & $-0.08^{\mathrm{ns}}$ & $0.08^{\mathrm{ns}}$ & $-0.01^{\mathrm{ns}}$ & $0.04^{\mathrm{ns}}$ \\
\hline \multirow{2}{*}{$\begin{array}{l}\text { Intramuscular fat } \\
\text { semimembranosus muscle (\%) }\end{array}$} & $0.00^{\mathrm{ns}}$ & $-0.17^{* * *}$ & $-0.16^{* * *}$ & $0.29^{* * *}$ \\
\hline & $0.01^{\mathrm{ns}}$ & $-0.11^{*}$ & $-0.16^{* *}$ & $0.35^{* * *}$ \\
\hline \multirow{2}{*}{$\begin{array}{l}\text { Intramuscular fat } \\
\text { longissimus dorsi muscle (\%) }\end{array}$} & $0.07^{\mathrm{ns}}$ & $-0.20^{* * *}$ & $-0.17^{\star * *}$ & $0.30^{* * *}$ \\
\hline & $0.09^{\text {ns }}$ & $-0.16^{* *}$ & $-0.16^{* *}$ & $0.37^{* * *}$ \\
\hline
\end{tabular}

${ }^{*} P<0.05,{ }^{* *} P<0.01,{ }^{* * *} P<0.001,{ }^{\text {ns }}$ non-significant $(P>0.05)$.

${ }^{\top}$ The first line gives the coefficient calculated with the complete data set $(n=475-500)$ and the second line gives the coefficient calculated without the Piétrain line $(n=381-400)$.

‡See Table 1 for legends.

cortisol concentrations and carcass composition parameters in Large White, Landrace and Meishan pigs, but not in Piétrain and Duroc pigs (Figure 2).

Cortisol concentrations measured in urine collected after unloading the animals were higher than in urine collected at the farm $(+278 \%, P<0.001)$ but the interaction between genetic line and sampling time (basal $v$. posttransportation) was not significant, showing that the increase (on a log scale) was not different in the five lines. The concentrations reached after transportation were within the range of concentrations measured in urine collected in the bladder from a group of pigs (Duroc $\times$ Large White F2 intercross) slaughtered under commercial conditions (Foury et al., 2005). The next morning cortisol concentrations in urine were still elevated (overall mean: $+62 \% \quad v$. basal concentrations), with large differences among lines (line $X$ day interaction, $P<0.01)$ : Landrace $+111 \%(P<0.001)$, Large White $+109 \% \quad(P<0.001), \quad$ Piétrain $+66 \%$ $(P<0.001)$, Duroc $+46 \%(P<0.001)$ and Meishan $+33 \%$ $(P<0.01)$.

Basal concentrations of catecholamines in urine also differed among lines $(P<0.001)$, although the range of variation was much smaller than for cortisol. For both adrenaline and noradrenaline, Large White pigs showed the lowest concentrations. The concentrations of all three stress hormones in urine were inter-correlated (cortisol $v$. adrenaline, $r=0.34$; cortisol $v$. noradrenaline, $r=0.31$; adrenaline $v$. noradrenaline, $r=0.38$, all $P<0.001$ ). For the most part, these correlations were not related to line differences since they were still highly significant after correction for batch and line $(r=0.33,0.21,0.37$, respectively, all $P<0.001$ ).

After transportation both adrenaline (overall mean: $+181 \%, \quad P<0.001$ ) and noradrenaline (overall mean: $+59 \%, P<0.001)$ concentrations were increased, with line $\times$ day interactions $(P<0.05)$, the largest increases being measured in the Piétrain and Meishan lines, and the lowest in Landrace and Large White. These concentrations were lower than the concentrations measured in urine collected in the bladder from a group of pigs (Duroc $X$ Large White F2 intercross) slaughtered under commercial conditions (Foury et al., 2005). The next morning, catecholamine concentrations were still higher than basal concentrations (overall mean: adrenaline $+77 \%$, noradrenaline $+32 \%, P<0.001)$, with no significant line $\times$ day interaction.

No significant correlation was found between catecholamine concentrations and meat $\mathrm{pH}$. On the other hand, when considering all the animals except Piétrain pigs, urinary catecholamine concentrations were positively correlated with adiposity. For instance, the correlation coefficients between PLEAN and adrenaline were $r=-0.16, \quad P<0.002, \quad n=398$ (basal concentrations); $r=-0.32, \quad P<0.001, \quad n=113 \quad$ (after transportation); $r=-0.33, P<0.001, n=187$ (the next morning); and with noradrenaline $r=-0.26, \quad P<0.001 ; \quad r=-0.24$, $P<0.01 ; r=-0.28, P<0.001$, respectively. Since cortisol and catecholamine concentrations were positively 
Foury, Geverink, Gil, Gispert, Hortós, Fonti Furnols, Carrion, Blott, Plastow and Mormède
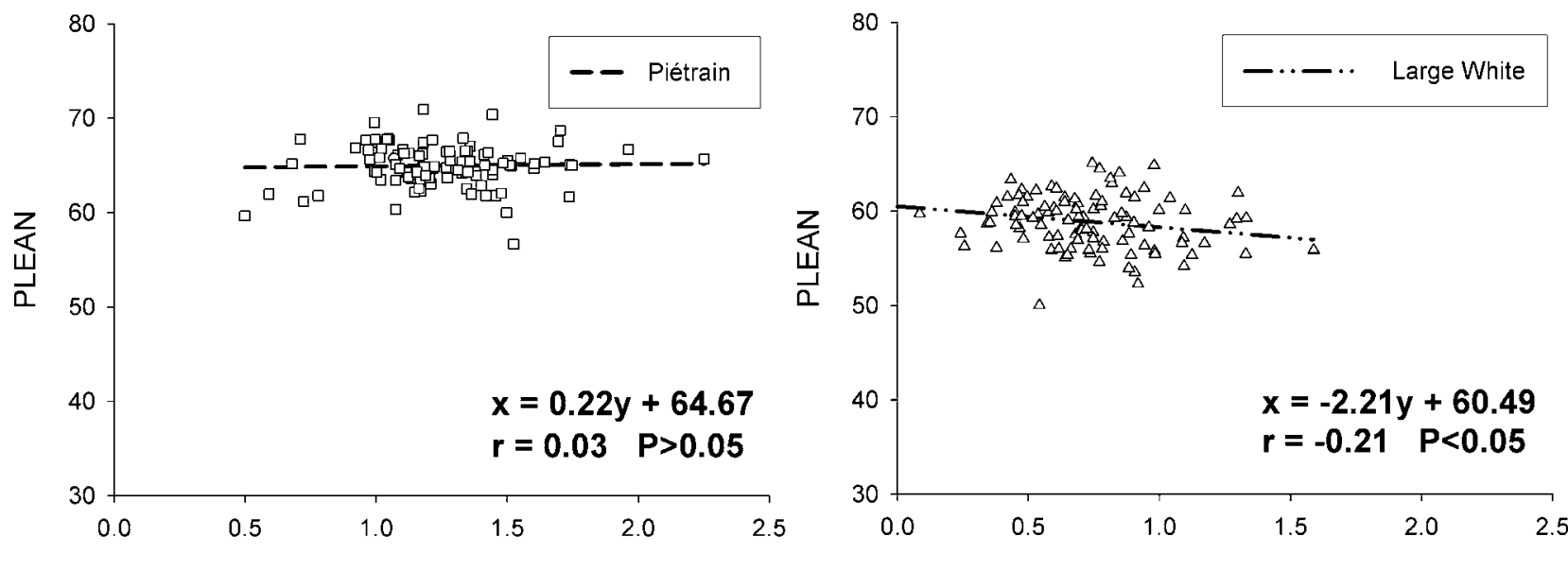

Log Cortisol (ng/mg creatinine)
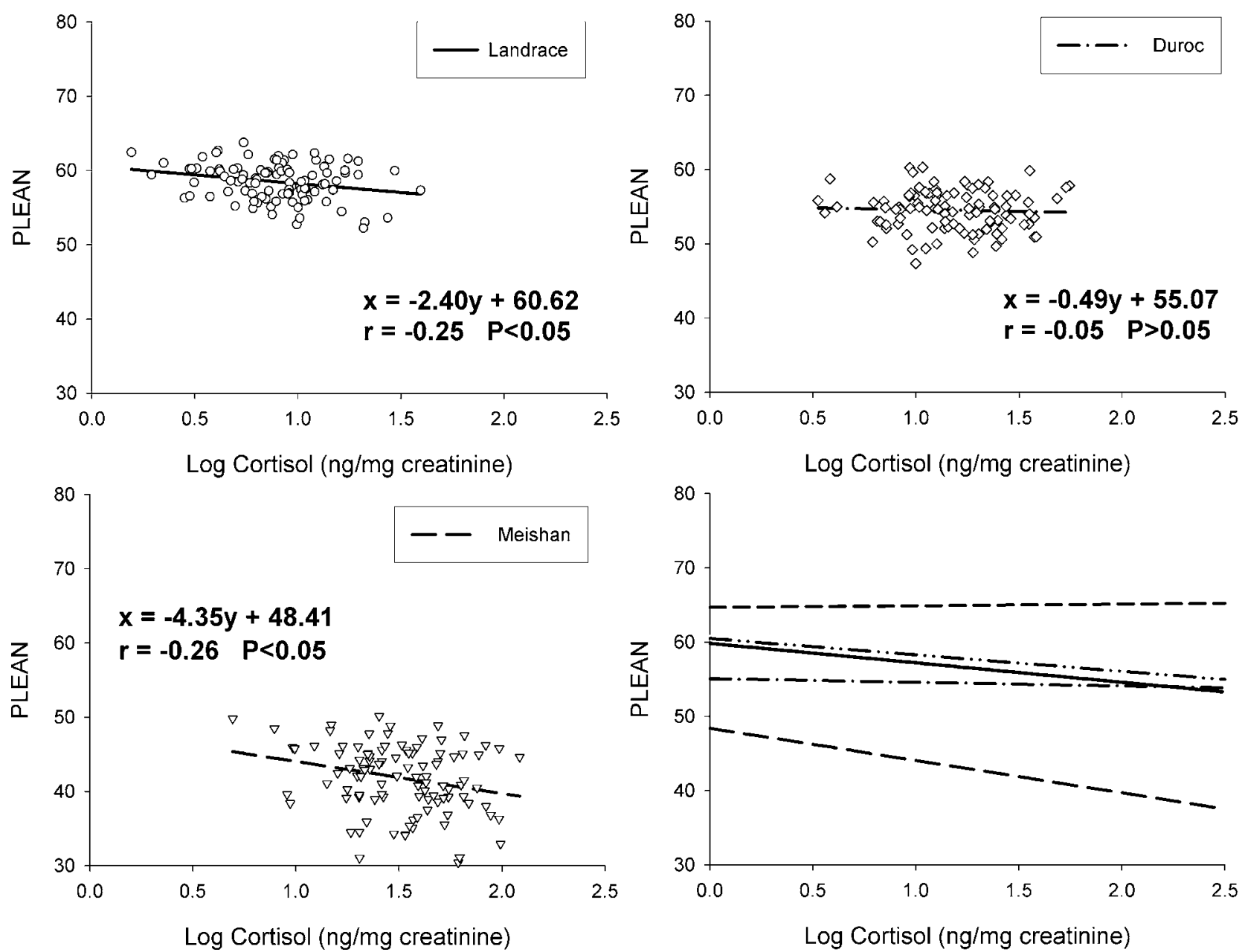

Figure 2 Scatterplot and regression line between estimated lean content of the carcass (PLEAN) and concentration of cortisol in urine (ng/mg creatinine, log scale) in the five breeds, and a synthetic representation of the regression lines (lower right frame).

correlated, the specific effect of catecholamine concentrations was also tested with cortisol concentrations included as a covariate (i.e. to correct for the effect of cortisol concentration per se). Different results were obtained for adrenaline and noradrenaline in relation to sampling time. The correlation coefficient between PLEAN and adrenaline was significant only with the levels measured in the morning before slaughter $(r=-0.25, P<0.01, n=183)$, and with noradrenaline the correlation coefficient was significant with the levels measured on farm $(r=-0.14$, $P<0.05 ; r=-0.10)$ and the morning before slaughter $(r=-0.28, P<0.001)$. 


\section{Discussion}

Stress hormones cortisol, adrenaline and noradrenaline play a major role in metabolic processes related to carcass composition and meat quality. Previously, we demonstrated in a segregating population between Large White and Duroc pigs the existence of phenotypic correlations between cortisol concentrations measured in urine collected after slaughter and fatness on one hand and between catecholamine concentrations and ultimate $\mathrm{pH}$ of meat on the other hand (Foury et al., 2005). The present experiment was designed to explore further the extent of genetic variation in stress-responsive neuroendocrine systems and its relationship with carcass composition and meat quality in pigs from five genetic lines covering a wide range of fatness.

An important component of the present experimental design, at variance with most published results, was the low level of stress experienced by the animals before and at slaughter, due to the very gentle handling of animals. Serum concentrations of cortisol and lactate, two sensitive indices of pre-slaughter stress, were much lower than the values measured under commercial conditions (e.g. Warriss et al., 1998; Pérez et al., 2002). Serum CK originates from striated muscle following an increase of membrane permeability that can be triggered for instance by physical exercise (Boyd, 1983; Schmidt and Schmidt, 1987; Volfinger et al., 1994). Since CK has a long half-life in plasma $(5.2 \pm 1.3 \mathrm{~h}$ in pigs) (Bickhardt, 1969), the concentrations measured at slaughter reflect the environmental effects during a longer period preceding slaughter, including the response to transportation. Altogether, the CK concentrations measured in the present study were low as compared with the concentrations measured in animals slaughtered under commercial conditions. The increase of CK activity with muscle content of the carcass is consistent with the fact that muscle is the major source of circulating CK. An interesting result is the relatively high concentration of CK activity measured in the Piétrain line, although all animals were negative for the allele of the ryanodine receptor gene responsible for malignant hyperthermia $(\mathrm{MH})$. $\mathrm{MH}$ can be triggered by halothane inhalation or acute stress (Fuji et al., 1991) and is accompanied by an increase of CK activity in plasma (Seewald et al., 1991; Richter et al., 1992; Klont et al., 1993). This indicates that the Piétrain line may carry other genetic mutations conferring muscular vulnerability to stress. Indeed a genetic heterogeneity has been described for MH susceptibility in pigs (Fletcher et al., 1993) and in humans (Deufel et al., 1992; Monnier et al., 2002).

Hormone concentrations measured in urine were also low, even after transportation, except for cortisol, when compared with the levels measured in animals handled and slaughtered under commercial conditions (Foury et al., 2005). This may explain why there was no relationship between catecholamine concentrations and meat $\mathrm{pH}$, the release of catecholamines before slaughter being probably too low to activate muscle glycogenolysis to a sufficient extent to influence glycogen levels and therefore ultimate pH (Monin, 2003). It is worth noting that after transportation, cortisol concentrations were within the range of the concentrations measured previously in Large White $\times$ Duroc pigs slaughtered under commercial conditions, but adrenaline concentrations were lower and noradrenaline very low. This may reflect a gradient of sensitivity of the different hormonal systems to stressors. Indeed, the cortisol response is very sensitive, even to low stimulation, and saturates quickly with increasing stimulus intensity. The mere exposure of an animal to a novel environment is sufficient to increase blood cortisol to its highest possible concentrations (Mormède and Dantzer, 1978), and low doses of corticotrophin-releasing factor saturate the cortisol response, although higher doses increase ACTH further (Zhang et al., 1990). Further studies should compare the sensitivity of the HPA axis and of the autonomic nervous system components to increasing stimulus intensity. However, at the current state of knowledge, the high concentrations of cortisol measured in urine after transportation reflect the exquisite sensitivity of the HPA axis to stressors rather than a high level of stress. These results further illustrate the interest of monitoring several biological parameters for a better evaluation of the stress level (Mormède, 2007; Mormède et al., 2007).

Large differences among lines could be measured in urinary cortisol concentrations, both under basal conditions and after stress, with a large range of variation. These results confirm and extend previous descriptions of variations in HPA axis activity and reactivity in different lines of pigs, the largest differences being measured between White breeds (low concentrations) and Meishan pigs or wild boars (high concentrations) (Bergeron et al., 1996; Désautés et al., 1997 and 1999; Hay and Mormède, 1998; Weiler et al., 1998; Rosochacki et al., 2000; Wise et al., 2001). It is worth noting that there was no significant difference (on a log scale) between genetic lines in the response to transportation. This means that the response to transportation stress is proportional to basal levels. Previously, we showed that the cortisol response to ACTH in Large White and Meishan pigs was proportional to basal concentrations (Désautés et al., 1999). These data suggest that the reactivity of the adrenal cortex to ACTH is an important mechanism explaining differences in cortisol levels (both basal and after stress) between genetic lines. Indeed, previous studies showed that the adrenal response to ACTH was an individual characteristic (Hennessy et al., 1988; Zhang et al., 1990 and 1992), and influenced by genetic factors (heritability $h^{2}=0.26$, estimated by half sib analysis on 357 litters from 24 boars) (D.C. Hennessy, personal communication). Altogether these data point to adrenal reactivity to ACTH as a major source of genetic variation in cortisol production.

Although significant, the correlation coefficients between serum and urinary concentrations of cortisol were rather low (serum v. urine: $r=0.19, n=495, P<0.001$ (basal); 
$r=0.29, n=146, P<0.001$ (post-transportation); $r=0.21$, $n=231, P<0.05$ (next morning)). Several factors may explain this result, including the influence of corticosteroidbinding globulin (CBG) concentrations that differ largely among and within strains (Marple et al., 1974; Ousova et al., 2004; Geverink et al., 2006; Guyonnet-Duperat et al., 2006). CBG levels influence cortisol concentrations in plasma, where the hormone is for the most part bound to CBG and influence much less cortisol concentrations in urine. This suggests urine is a better matrix to measure hormone production (Bright and Darmaun, 1995; Dhillo et al., 2002).

The most important result relates to the co-variation between cortisol concentrations and carcass composition, both between and within lines, with some exceptions. The general pattern is that the content of fat increases - and therefore the content of muscle decreases - with increasing concentrations of cortisol. This relationship reflects the effects of cortisol on metabolism since cortisol favours the storage of lipids (in the presence of insulin) at the expense of proteins, via peripheral catabolism and hepatic neoglucogenesis (Devenport et al., 1989; Dallman et al., 1993). Across lines (without the Piétrain pigs), the correlation coefficient reached -0.46 (PLEAN v. cortisol concentration in urine collected on farm), so that approximately $21 \%$ of variation in fatness could be explained by variations in cortisol production. This proportion was much lower within lines (up to 7\%), eventually because less polymorphic genes are segregating within than across lines. The Piétrain line used in the present study does not fit in this general scheme, with its relatively high concentrations of cortisol, similar to the concentrations found in Duroc pigs (Rosochacki et al., 2000), despite its extreme leanness. One explanation may be that the corticosteroid receptors that mediate the metabolic effect of cortisol are relatively insensitive to their ligand; it would also explain the absence of correlation between cortisol concentrations and carcass composition in the Piétrain line. Indeed large genetic variations of receptor efficiency and their metabolic implications have been described, e.g. in humans (DeRijk et al., 2002) and rats (Marissal-Arvy et al., 2004). The functionality of corticosteroid receptors will have to be explored in similar Piétrain-line pigs to confirm this hypothesis.

The relationship found between catecholamines and leanness is more difficult to understand and interpret. Part of this relationship results from the coupling between catecholamine and cortisol secretion. This is especially true for adrenaline, the synthesis of which is under control of cortisol that induces phenylethanolamine $N$-methyltransferase, the enzyme converting noradrenaline into adrenaline in the adrenal medulla (Ciaranello, 1978). However, noradrenaline basal concentrations and both catecholamines measured the morning after transport when the animals were in a state of fasting were negatively correlated with leanness, even after correction for cortisol concentrations. This relation is opposite to the effect of catecholamines on protein anabolism (Navegantes et al., 2002), and could rather be related to a differential resistance to fasting.

Indeed, serum glucose concentrations measured at slaughter when animals were in the fasting state were positively correlated with leanness and negatively with fatness. This result is consistent with the effect of insulin that favors the use of glucose for the synthesis of fat in adipose tissue. In previous experiments, we showed that the sensitivity to insulin was much larger in Meishan than in Large White pigs, since after injection of glucose, its clearance from circulation was identical in the two lines, but peak insulin concentrations were twice as high in Large White pigs ( $C$. Désautés and P. Mormède, unpublished results). It is also consistent with the study of Bonneau (1993) who found that the decline in plasma glucose concentrations after insulin challenge was similar between Meishan and Large White breeds, but the duration of the decrease of plasma glucose concentrations was longer in Meishan pigs. In the present experiment, we tried to measure serum insulin in a subset of animals, but the concentrations were very low and around the limit of detection of the assay as expected in fasting animals, so that no difference between lines could be found. Dynamic testing should be done in these lines to explore this endocrine system and its interaction with cortisol (Dallman et al., 1993).

The present data illustrate the fact that several mechanisms regulate energy fluxes in the body and the resulting storage of excess energy as fat stores. They also show that these mechanisms are strongly influenced by genetic factors so that selection for lean carcasses may lead to important changes in the functioning of basic endocrine systems that are necessary for a whole range of physiological regulations including responses to stress. For instance, cortisol concentrations have been shown to be the strongest biological predictor of the estimated breeding value for piglet survival (Leenhouwers et al., 2002), and this may be one factor explaining the high survival rate of Meishan piglets despite their larger litter size and smaller birth weight, as compared with Large White or Landrace (Legault and Caritez, 1982). A better understanding of these processes and the exploration of the molecular mechanisms underlying genetic variation (Ousova et al., 2004; GuyonnetDuperat et al., 2006; Murani et al., 2006) will allow to optimise selection for carcass composition and meat quality but spare basic endocrine mechanisms that are necessary for survival and adaptation.

\section{Acknowledgements}

The present results were obtained as part of a larger research project (http://www.qualityporkgenes.com) supported by the European Commission under the Fifth Framework Programme (http://www.cordis.lu/life), contract number QLK5-CT-200101888. This paper is the work of the authors and does not necessarily represent the position of the Commission. 


\section{References}

Bergeron R, Gonyou HW and Eurell TE 1996. Behavioral and physiological responses of Meishan, Yorkshire and crossbred gilts to conventional and turn-around gestation stalls. Canadian Journal of Animal Science 76, 289-297.

Bickhardt K 1969. Ein enzymatisches verfahren zur erkennung von muskelschäden beim lebenden schwein. Deutsche Tierärztliche Wochenschrift 76, 601-624.

Bidanel JP, Caritez JC, Gruand J and Legault C 1993. Growth, carcass and meat quality performance of crossbred pigs with graded proportions of Meishan genes. Genetics, Selection, Evolution 25, 83-99.

Bonneau M 1993. Growth hormone response to GRF and insulin-induced hypoglycemia in yorkshire and Meishan pigs. American Journal of Physiology 264, E54-E59.

Boyd JW 1983. The mechanisms relating to increases in plasma enzymes and isoenzymes in diseases of animals. Veterinary Clinical Pathology 12, 9-24.

Bright GM and Darmaun D 1995. Corticosteroid-binding globulin modulates cortisol concentration responses to a given production rate. Journal of Clinical Endocrinology and Metabolism 80, 764-769.

Ciaranello RD 1978. Regulation of phenylethanolamine $\mathrm{N}$-methyltransferase. Biochemical Pharmacology 27, 1895-1897.

Crockett CM, Bowers CL, Sackett GP and Bowden DM 1993. Urinary cortisol responses of longtailed macaques to five cage sizes, tethering, sedation and room change. American Journal of Primatology 30, 55-74.

Dallman MF, Strack AM, Akana SF, Bradbury MJ, Hanson ES, Scribner KA and Smith M 1993. Feast and famine: critical role of glucocorticoids with insulin in daily energy flow. Frontiers in Neuroendocrinology 14, 303-347.

DeRijk RH, Schaaf M and de Kloet ER 2002. Glucocorticoid receptor variants: clinical implications. Journal of Steroid Biochemistry and Molecular Biology 81, 103-122.

Désautés C, Bidanel JP and Mormède P 1997. Genetic study of behavioral and pituitary-adrenocortical reactivity in response to an environmental challenge in pigs. Physiology and Behavior 62, 337-345.

Désautés C, Sarrieau A, Caritez JC and Mormède $P$ 1999. Behavior and pituitary-adrenal function in Large White and Meishan pigs. Domestic Animal Endocrinology 16, 193-205.

Deufel T, Golla A, lles D, Meindl A, Meitinger T, Schindelhauer D, DeVries A, Pongratz D, MacLennan DH, Johnson KJ and Lehman-Horn F 1992. Evidence for genetic heterogeneity of malignant hyperthermia susceptibility. American Journal of Human Genetics 50, 1151-1161.

Devenport L, Knehans A, Sundstrom A and Thomas T 1989. Corticosterone's dual metabolic actions. Life Sciences 45, 1389-1396.

Dhillo WS, Kong WM, Le Roux CW, Alaghband-Zadeh J, Jones J, Carter G, Mendoza N, Meeran K and O'Shea D 2002. Cortisol-binding globulin is important in the interpretation of dynamic tests of the hypothalamic-pituitary-adrenal axis. European Journal of Endocrinology 146, 231-235.

Fernandez $X$ and Tornberg E 1991. A review of the causes of variation in muscle glycogen content and ultimate $\mathrm{pH}$ in pigs. Journal of Muscle Foods 2 , 209-235.

Fletcher JE, Calvo PA and Rosenberg H 1993. Phenotypes associated with malignant hyperthermia susceptibility in swine genotyped as homozygous or heterozygous for the ryanodine receptor mutation. British Journal of Anaesthesia 71, 410-417.

Foury A, Devillers N, Sanchez MP, Griffon H, Le Roy P and Mormède P 2005. Stress hormones, carcass composition and meat quality in Large White $X$ Duroc pigs. Meat Science 69, 703-707.

Fuji J, Otsu K, Zorzato F, De Leon S, Khanna VK, Weiler JE, O'Brien PJ and MacLennan DH 1991. Identification of a mutation in porcine ryanodine receptor associated with malignant hyperthermia. Science 253, 448-451.

Geverink NA, Foury A, Plastow GS, Gil M, Gispert $M$, Hortos $M$, Font i Furnols M, Gort G, Moisan MP and Mormède P 2006. Cortisol-binding globulin and meat quality in five European lines of pigs. Journal of Animal Science 84, 204-211.

Gispert M and Diestre A 1994. Classement des carcasses de porc en Espagne: un pas vers I'harmonisation communautaire. Techniporc 17, 29-32.

Guyonnet-Duperat V, Geverink N, Plastow GS, Evans G, Ousova 0, Croisetière $C$, Foury A, Richard E, Mormède P and Moisan MP 2006. Functional implication of an Arg307Gly substitution in corticosteroid-binding globulin, a candidate gene for a quantitative trait locus associated with cortisol variability and obesity in pig. Genetics 173, 2143-2149.

Hay $M$ and Mormède $P$ 1997a. Determination of catecholamines and methoxycatecholamines excretion patterns in pig and rat urine by ionexchange liquid chromatography with electrochemical detection. Journal of Chromatography B: Biomedical Sciences and Applications 703, 15-23.

Hay $M$ and Mormède $P$ 1997b. Improved determination of urinary cortisol and cortisone, or corticosterone and 11-dehydrocorticosterone by highperformance liquid chromatography with ultraviolet absorbance detection. Journal of Chromatography B: Biomedical Sciences and Applications 702, 33-39.

Hay $M$ and Mormède $P$ 1998. Urinary excretion of catecholamines, cortisol and their metabolites in Meishan and Large White sows: validation as a non invasive and integrative assessment of adrenocortical and sympathoadrenal axis activity. Veterinary Research 29, 119-128.

Hennessy DP, Stelmasiak T, Johnston NE, Jackson PN and Outch KH 1988. Consistent capacity for adrenocortical response to ACTH administration in pigs. American Journal of Veterinary Research 49, 1276-1283.

Klont RE, Lambooy E and Van Logtestijn JG 1993. Effect of preslaughter anesthesia on muscle metabolism and meat quality of pigs of different halothane genotypes. Journal of Animal Science 71, 1477-1485.

Leenhouwers JI, Knol EF, De Groot PN, Vos H and Van der Lende T 2002. Fetal development in the pig in relation to genetic merit for piglet survival. Journal of Animal Science 80, 1759-1770.

Legault Cvand Caritez JC 1982. Premier bilan de l'expérimentation sur le porc chinois en France. 1- Performances de reproduction en race pure et en croisement. Journées de la Recherche Porcine en France 14, 127-136.

Marissal-Arvy N, Lombes M, Petterson J, Moisan MP and Mormède P 2004. Gain of function mutation in the mineralocorticoid receptor of the Brown Norway rat. Journal of Biological Chemistry 279, 39232-39239.

Marple DN, Cassens RG, Topel DG and Christian LL 1974. Porcine corticosteroid-binding globulin: binding properties and levels in stresssusceptible swine. Journal of Animal Science 38, 1224-1228.

Monin $\mathrm{G} 2003$. Abattage des porcs et qualités des carcasses et des viandes. INRA Productions Animales 16, 251-262.

Monnier N, Krivosic-Horber R, Payen JF, Kozak-Ribbens G, Nivoche $Y$, Adnet $P$, Reyford $\mathrm{H}$ and Lunardi $\mathrm{J}$ 2002. Presence of two different genetic traits in malignant hyperthermia families: implication for genetic analysis, diagnosis, and incidence of malignant hyperthermia susceptibility. Anesthesiology 97, 1067-1074.

Mormède $P$ 2007. Assessment of pig welfare. In The welfare of pigs (ed. L Faucitano, J Ludke and 0 Dalla Costa), in press.

Mormède $P$ and Dantzer $R$ 1978. Behavioural and pituitary-adrenal characteristics of pigs differing by their susceptibility to the malignant hyperthermia syndrome induced by halothane anesthesia. 2. Pituitary-adrenal function. Annals of Veterinary Research 9, 569-576.

Mormède $P$, Andanson $S$, Auperin $B$, Beerda $B$, Guémené $D$, Malmkvist $J$, Manteca X, Manteuffel G, Prunet $P$, Van Reenen CG, Richard $S$, and Veissier 2007. Exploration of the hypothalamic-pituitary-adrenal function as a tool to evaluate animal welfare. Physiology and Behavior, doi:10.1016/j.physbeh. 2006.12.003, in press.

Murani E, Ponsuksili S, Schellander K and Wimmers K 2006. Association of corticotropin-releasing hormone gene variation with performance and meat quality traits in commercial pig lines. Animal Genetics 37, 509-512.

Navegantes LCC, Migliorini RH and Kettelhut IC 2002. Adrenergic control of protein metabolism in skeletal muscle. Current Opinion in Clinical Nutrition and Metabolic Care 5, 281-286.

Ousova 0 , Guyonnet-Duperat V, lannuccelli N, Bidanel JP, Milan D, Genet $C$, Llamas B, Yerle $M$, Gellin J, Chardon $P$, Emptoz-Bonneton A, Pugeat $M$, Mormède $P$ and Moisan MP 2004. Corticosteroid binding globulin: a new target for cortisol-driven obesity. Molecular Endocrinology 18, 1687-1696.

Pérez MP, Palacio J, Santolaria MP, Acena MC, Chacon G, Verde MT, Calvo JH, Zaragoza MP, Gascon M and Garcia-Belenguer S 2002. Influence of lairage time on some welfare and meat quality parameters in pigs. Veterinary Research 33, 239-250.

Plastow GS, Carrión D, Gil M, García-Regueiro JA, Font i Furnols M, Gispert M, Oliver MA, Velarde $A$, Guàrdia MD, Hortós $M$, Rius MA, Sárraga $C$, Díaz $I$, Valero A, Sosnicki A, Klont R, Dornan S, Wilkinson JM, Evans G, Sargent $C$, Davey G, Connolly D, Houeix B, Maltin CM, Hayes HE, Anandavijayan V, Foury A, 


\section{Foury, Geverink, Gil, Gispert, Hortós, Fonti Furnols, Carrion, Blott, Plastow and Mormède}

Geverink N, Cairns M, Tilley RE, Mormède P and Blott SC 2005. Review. Quality pork genes and meat production. Meat Science 70, 409-421.

Pomar C, Rivest J, Jean dit Bailleul P and Marcoux M 2001. Predicting loin-eye area from ultrasound and grading probe measurements of fat and muscle depths in pork carcasses. Canadian Journal of Animal Science 81, 429-434.

Richter A, Gerdes C and Loscher W 1992. Atypical reactions to halothane in a subgroup of homozygous malignant hyperthermia ( $\mathrm{MH}$ )-susceptible pigs: indication of a heterogenous genetic basis for the porcine syndrome. Deutsche Tierärztliche Wochenschrift 99, 401-406.

Rosochacki SJ, Piekarzewska AB, Poloszynowicz J and Sakowski T 2000. The influence of restraint immobilization stress on the concentration of bioamines and cortisol in plasma of Pietrain and Duroc pigs. Journal of Veterinary Medicine Series A 47, 231-242.

Scheurink $A J$ and Steffens $A B$ 1990. Central and peripheral control of sympathoadrenal activity and energy metabolism in rats. Physiology and Behavior 48, 909-920.

Schmidt E and Schmidt FW 1987. Enzyme release. Journal of Clinical Chemistry and Clinical Biochemistry 25, 525-540.

Seewald MJ, Eichinger HM, Lehman-Horn F and laizzo PA 1991. Characterization of swine susceptible to malignant hyperthermia both in vivo, in vitro and post-mortem techniques. Acta Anaesthesiologica Scandinavica 35, 345-349.

Statistical Analysis Systems Institute 2000. Staistics version 8.02. SAS Inst., Inc., Cary, NC.
Volfinger L, Lassourd V, Michaux JM, Braun JP and Toutain PL 1994. Kinetic evaluation of muscle damage during exercise by calculation of creatine kinase released. American Journal of Physiology 266, R434-R441.

Walstra P and Merkus GSM 1995. Procedure for the assessment of lean meat percentage as a consequence of the new EU reference dissection method in pig carcass classification. DLO - Research Institute of Animal Science and Health (ID-DLO), Zeist, The Netherlands.

Warriss PD, Brown SN, Edwards JE and Knowles TG 1998. Effect of lairage time on levels of stress and meat quality in pigs. Animal Science 66, 255-261.

Weiler U, Claus R, Schnoebelen-Combes S and Louveau I 1998. Influence of age and genotype on endocrine parameters and growth performance: a comparative study in Wild boars, Meishan and Large White boars. Livestock Production Science 54, 21-31.

Wise T, Klindt J, Howard HJ, Conley AJ and Ford JJ 2001. Endocrine relationships of Meishan and White composite females after weaning and during the luteal phase of the estrous cycle. Journal of Animal Science 79, 176-187.

Zhang SH, Hennessy DP and Cranwell PD 1990. Pituitary and adrenocortical responses to corticotropin-releasing factor in pigs. American Journal of Veterinary Research 51, 1021-1025.

Zhang SH, Hennessy DP, Cranwell PD, Noonan GJ and Francis HJ 1992. Physiological responses to exercise and hypoglycemia stress in pig of differing adrenal responsiveness. Comparative Biochemistry and Physiology (A) 103, 695-703. 